\title{
Critical analysis of acute kidney injury in pediatric COVID-19 patients in the intensive care unit
}

\author{
Rupesh Raina ${ }^{1,2,3}$ (I) $\cdot$ Ronith Chakraborty ${ }^{1,2} \cdot$ Isabelle Mawby ${ }^{1} \cdot$ Nirav Agarwal $^{1} \cdot$ Sidharth Sethi $^{4} \cdot$ Michael Forbes $^{5}$
}

Received: 21 February 2021 / Revised: 25 March 2021 / Accepted: 7 April 2021 / Published online: 29 April 2021

(C) IPNA 2021

\begin{abstract}
Background and objectives COVID-19 is responsible for the 2019 novel coronavirus disease pandemic. Despite the vast research about the adult population, there has been little data collected on acute kidney injury (AKI) epidemiology, associated risk factors, treatments, and mortality in pediatric COVID-19 patients admitted to the ICU. AKI is a severe complication of COVID-19 among children and adolescents.

Methods A comprehensive literature search was conducted in PubMed/MEDLINE and Cochrane Center Trials to find all published literature related to AKI in COVID-19 patients, including incidence and outcomes.

Results Twenty-four studies reporting the outcomes of interest were included. Across all studies, the overall sample size of COVID positive children was 1,247 and the median age of this population was 9.1 years old. Among COVID positive pediatric patients, there was an AKI incidence of $30.51 \%$, with only $0.56 \%$ of these patients receiving KRT. The mortality was $2.55 \%$ among all COVID positive pediatric patients. The incidence of multisystem inflammatory syndrome in children (MIS-C) among COVID positive patients was $74.29 \%$.

Conclusion AKI has shown to be a negative prognostic factor in adult patients with COVID-19 and now also in the pediatric cohort with high incidence and mortality rates. Additionally, our findings show a strong comparison in epidemiology between adult and pediatric COVID-19 patients; however, they need to be confirmed with additional data and studies.
\end{abstract}

Keywords COVID-19 · Acute kidney injury $\cdot$ Kidney replacement therapy $\cdot$ Adult $\cdot$ Pediatric $\cdot$ MIS-C

Rupesh Raina and Ronith Chakraborty are Co-first author

Rupesh Raina

rraina@akronchildrens.org; raina@akronnephrology.com

1 Department of Nephrology, Akron Nephrology Associates/ Cleveland Clinic Akron General, Akron, OH, USA

2 Department of Nephrology, Akron Children's Hospital, Akron, OH, USA

3 School of Medicine, Case Western Reserve University, Cleveland, OH, USA

4 Pediatric Nephrology, Kidney Institute, Medanta, The Medicity Hospital, Gurgaon, Haryana, India

5 Director of Clinical Research and Outcomes Analysis, Department of Pediatrics, Akron Children's Hospital, Akron, OH, USA

\section{Introduction}

Since January 30, 2020, the virus known as severe acute respiratory syndrome coronavirus 2 (SARS-CoV-2) or COVID19 was declared a global health emergency of international concern by the World Health Organizations (WHO) and has continued to evolve into a devastating pandemic [1]. COVID19 has infected more than 103 million people of all ages and has a mortality of 2.3 million people globally as of February 2020 (John Hopkins Coronavirus Tracker). We have extensively developed our knowledge on the pathophysiology, diagnosis, management, and post infection complications of COVID-19 in the past year; however, this knowledge continues to evolve. While the majority (approximately 80\%) of adult patients with COVID-19 have mild symptoms, the virus may produce severe illness, multiorgan failure, and death in a small portion of the population [2]. Kidney manifestations of COVID-19, such as acute kidney injury (AKI), are typically considered negative prognostic factors and may appear in up 
to $25 \%$ of adult patients. The disease is most severe among those who have comorbidities or those who are elderly [3, 4].

Limited research on the epidemiology and manifestations of COVID-19 among pediatric patients has been reported to be much different than that of adults. As reported recently, children only comprise about $1-2 \%$ of COVID-19 cases documented worldwide [5]. In a recent meta-analysis of 9,335 pediatric COVID-19 patients, $13.1 \%$ of the patients presented asymptomatically through contact exposure in family clusters [6]. Overall, $57.4 \%$ of patients were hospitalized and at least one underlying comorbidity was reported in $27.1 \%$ of cases [6]. The neonatal age group, male gender, lower respiratory tract disease, and preexisting medical conditions have all been associated with severe disease among children [5]. The most common clinical features of COVID-19 in pediatric patients are fever, dry cough, and pneumonia along with an increasing prevalence of multisystem involvement, including AKI among other kidney manifestations [7]. Thus far, among pediatric COVID cases presenting with the same severity of illness as adults, a similar clinical picture of kidney involvement may be expected [8].

Furthermore, multisystem inflammatory syndrome in children (MIS-C) is a life-threatening complication of the virus specifically among children. MIS-C is associated with SARS-CoV-2 and has been shown to occur within 2-4 weeks, most commonly after an infection $[9,10]$. Children with MIS-C have been reported to exhibit symptoms similar to those of Kawasaki disease including fever, toxic shock syndrome, macrophage activation syndrome, secondary hemophagocytic lymphohistiocytosis, and multisystem organ involvement, which commonly includes AKI $[9,11,12]$.

Despite this data, there is a lack of large-scale studies analyzing the extent of AKI in pediatric patients. Thus, this systematic review aims to evaluate the incidence of AKI, associated mortality, the need for kidney replacement therapy (KRT), and outcomes in the pediatric COVID-19 population through the analysis of published literature.

\section{Method}

\section{Database sources and search strategy}

This study was registered with the International Prospective Register for Systematic Reviews (PROSPERO: CRD42021237695). In this study, a systemic search was performed in PubMed/MEDLINE and Cochrane Center Trials databases to find all published literature related to AKI in COVID-19 patients, including incidence and outcomes. The search terms for the pediatric population included "COVID19", "Coronavirus", "Betacoronavirus", "kidney", "renal", "pediatric", "acute kidney injury", and "MISC" in the search criteria (Appendix A). All literature from the search strategy was then imported into Rayyan QCRI using EndNote. In addition, the reference lists of the selected studies were further reviewed for any additional publications that were relevant to the search criteria. The search for the pediatric literature spanned from November 1, 2019 to December 24, 2020. Language restriction of only English studies was applied. This systematic review was performed according to the Preferred Reporting Items for Systematic Reviews and Meta-Analyses "PRISMA" checklist (Appendix B).

\section{Literature selection}

The pediatric literature was independently reviewed by two reviewers using the inclusion and exclusion criteria with a third reviewer to settle any disputes. The inclusion criteria for the publications of pediatric populations included prospective, retrospective, and case series studies assessing AKI in COVID-19 positive patients. All included studies needed to contain laboratory-confirmed SARS-CoV-2 diagnosis (via detection of SARS-CoV-2 nucleic acid via polymerase-chain-reaction), demographic and epidemiological data (incidence of AKI, severity, and comorbidities), and outcome. Males and females $\leq$ 24 years were the criteria for the pediatric population. Studies exclusively on kidney transplant patients or a negative SARS-CoV-2 status were excluded along with systematic reviews, meta-analyses, animal studies, and letters not presenting any original data (Table 1).

\section{Quality assessment}

All included studies were evaluated for study quality independently using a quality assessment tool from the National Heart Lung and Brain Institute (NHLBI) (https://www. nhlbi.nih.gov/health-topics/study-quality-assessmenttools). This tool is designed to validate the internal studies designed for critical appraisal. The study quality had eight questions: study objective, study population, case definition, consecutive cases, outcome validity, adequate length of follow-up, statistical methods, and results. Studies were scored out of 8 points, where $6-8$ points were considered good quality, $4-5$ as fair quality, and $<$ 4 were regarded as poor quality.

\section{Data extraction and statistical analysis}

Data regarding patient demographics, the presence of comorbidities, AKI incidence, mortality rates, need for KRT, and outcomes were recorded electronically. The pooled proportions for these outcomes and their respective $95 \%$ confidence intervals $(95 \% \mathrm{CI})$ were assessed for each study or calculated when not reported. The degree of between-study statistical heterogeneity was assessed using the $\mathrm{I}^{2}$ test, where $\mathrm{I}^{2} \geq 50 \%$ indicated high heterogeneity. A meta-analysis of the outcomes was performed with overall pooled estimates calculated with a 
Table $1 \quad$ PICO table

\begin{tabular}{lll}
\hline Criteria & Inclusion criteria & Exclusion criteria \\
\hline Population & Any pediatrics population $(<24$ years $)$ & \\
Intervention/input exposure & SARS-CoV-2 diagnostic test & Negative SARS-CoV-2 test \\
Comparison & AKI incidence in COVID positive children population. & \\
Outcomes & Pediatric patients who are COVID + and have AKI & \\
Study types & Prospective/retrospective studies, case studies & Systematic review, meta analyses, animal studies \\
\hline
\end{tabular}

random effects model and fixed effects model to assess for high and low heterogeneity, respectively. Forest plots were utilized to visualize the outcomes of each study, including the combined estimated outcomes with their 95\% CI. Funnel plots were created to graphically assess publication bias in each study. A $p$ value $\leq 0.05$ was used to consider statistical significance. All statistical analyses were performed with $\mathrm{R}$ software version 3.1.0.

\section{Results}

\section{Study selection and details}

The database search for the pediatric population yielded a total of 42 studies with 24 studies included that reported the outcomes of interest (Fig. 1). Of these studies, 10 were retrospective cohort studies, 7 were case reports, 4 were case series, 2 were cross-sectional studies, and one was a prospective cohort study [12-35]. There were 23 studies that were determined to be of good quality while one study was of fair quality [S. Table 1]. However, only a total of 14 pediatric studies were used for our meta-analysis as the other studies had total sample sizes less than 10. The overall sample size of COVID positive children across the studies was 1,247 (ranging from 17 to 570 across 14 different studies). The pooled median age of children was 9.1 years (median of 6.5-14.5 years across all studies) and $56.2 \%$ of patients were male. The values pertaining to the distribution of race among the pediatric patients was reported to be African American (29.1\%), Caucasian (16.4\%), Asian (3.4\%), and a category for unknown/missing patients $(51.1 \%)$. A total of $26.7 \%$ of children had at least 1 pre-existing co-morbidity (based on 20 studies). The data for various lab parameters among these patients were very limited including glomerular filtration rate (1 study), serum creatinine (median: $62.5 \mu \mathrm{mol} / \mathrm{L}(0.71 \mathrm{mg} /$ dL); 6 studies), blood urea nitrogen, D-dimer (median $2.7 \mathrm{mg} /$ L (0.27 mg/dL); 8 studies), sodium (median $132.5 \mathrm{mEq} / \mathrm{L} ; 3$ studies), and potassium (1 study). Also, only one study reported the data for uremia, proteinuria, and hematuria. The details of the studies are provided in Tables 2 and 3.

\section{Data analysis}

This meta-analysis for the outcomes of interest was conducted for studies with total sample sizes $\geq 10$ (14 studies; $\mathrm{n}=1,247)$. Through our analysis, the pooled $(95 \% \mathrm{CI})$ AKI incidence in COVID positive pediatric patients was $30.51 \%(21.84-39.94 \%)\left[\mathrm{I}^{2}=89.8 \%\right.$ (84.65 to $93.21 \%$ ); $\mathrm{p}<0.0001$; random effects; 14 studies; $\mathrm{n}=1,247$ ] [Table 4; Figs. 2 and 3]. Additionally, our analysis showed a pooled mortality $(95 \% \mathrm{CI})$ of $2.55 \%(1.67-3.73 \%)\left[\mathrm{I}^{2}=38.72 \%(0.00\right.$ to $70.77 \%) ; \mathrm{p}$ $=0.0999 ;$ fixed effects; 10 studies; $\mathrm{n}=989]$ in COVID positive patients [Table 5; Figs. 4 and 5]. Only four studies reported the use of KRT in COVID pediatric

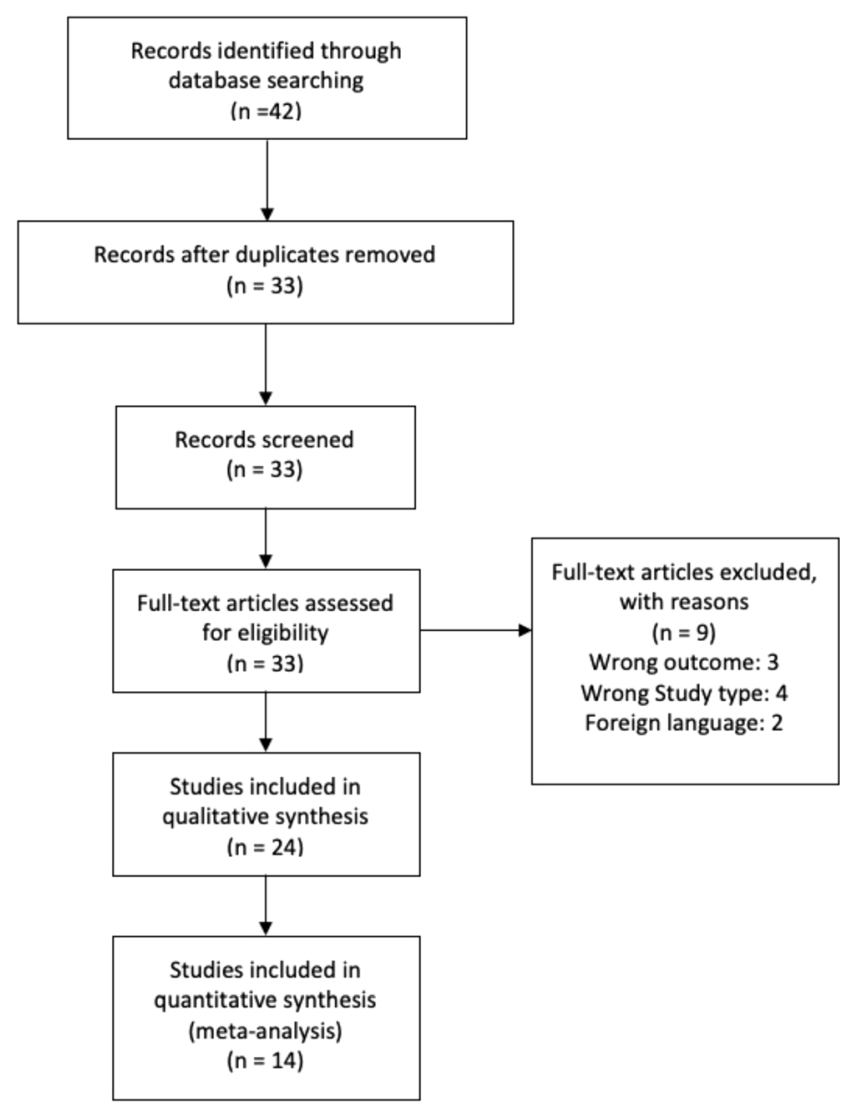

Fig. 1 Prisma flowchart for pediatric studies 


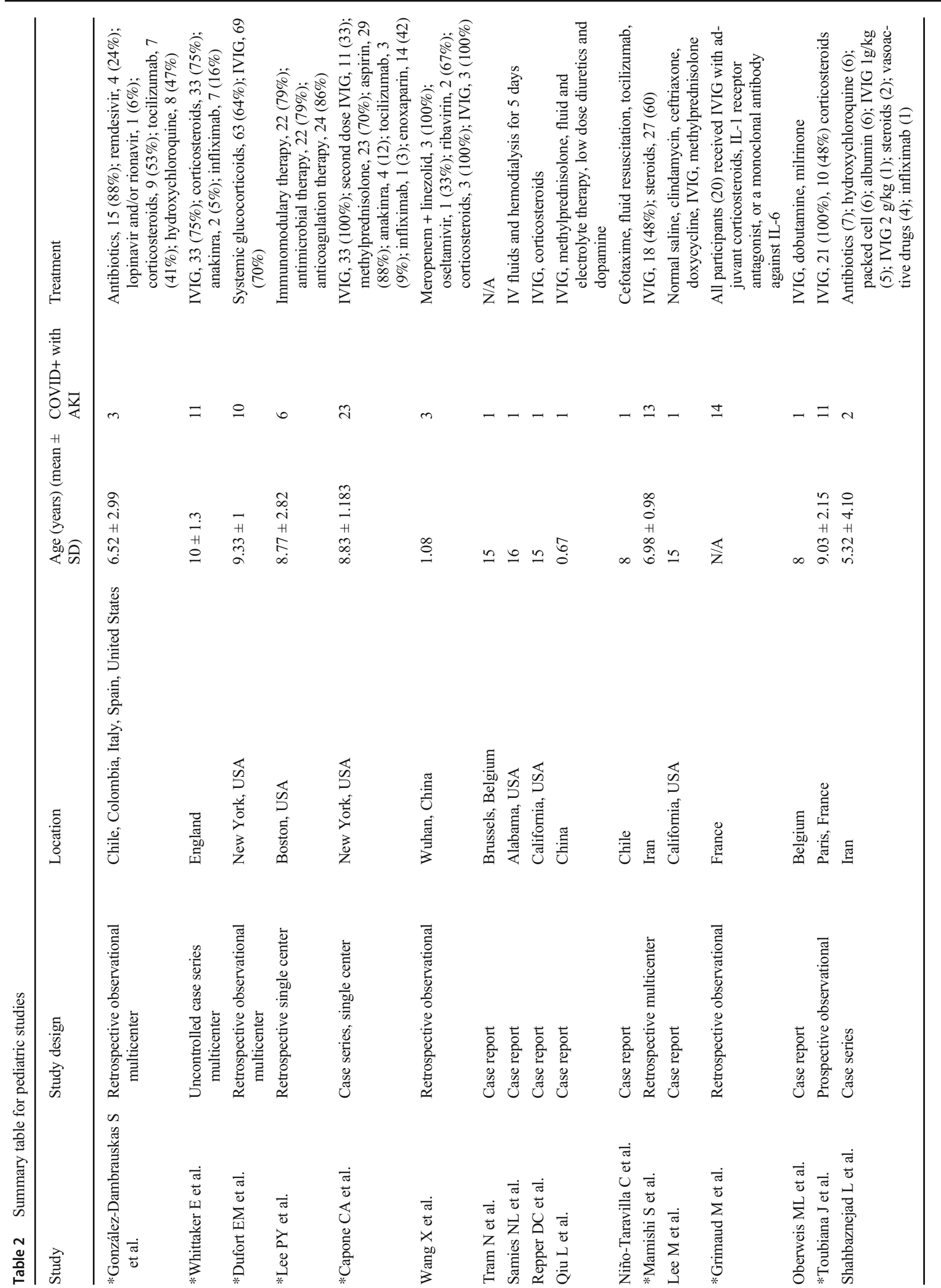




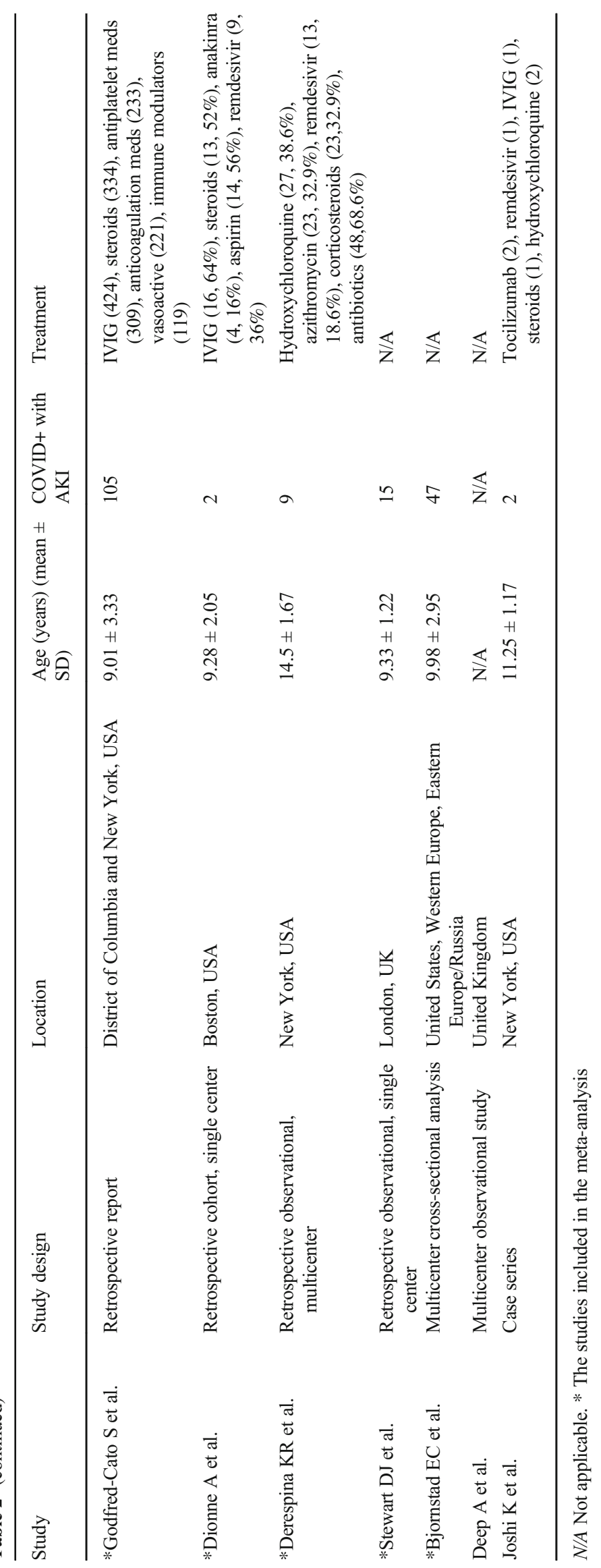


patients with AKI. The pooled proportion (95\% CI) of AKI COVID positive patients receiving KRT was $0.56 \%(0.16-1.43 \%)\left[\mathrm{I}^{2}=0 \%(0.00\right.$ to $76.45 \%) ; \mathrm{p}=$ 0.6493; fixed effects; 4 studies; $\mathrm{n}=712$ ].

The distribution of various treatments and intervention modalities was also assessed in this study. The analysis showed that the pooled proportion $(95 \% \mathrm{CI})$ of COVID positive patients receiving respiratory support was $46.33 \%(24.99-68.40 \%)$ [p < 0.0001; random effects; 12 studies; $\mathrm{n}=1,086]$ while $53.96 \%(34.43-$ $72.88 \%$ ) of patients received inotropic support $[\mathrm{p}<0.0001$; random effects; 6 studies; $\mathrm{n}=191]$. The other supportive treatments are described in Table 2. It was evaluated that the median duration of hospital stay among COVID positive patients was 6 days (median of 4-8 days across 7 studies providing the data). Lastly, this meta-analysis evaluated the incidence of MIS-C among COVIDpositive patients and found a pooled incidence $(95 \% \mathrm{CI})$ of $74.29 \%(41.24-96.43 \%)\left[\mathrm{I}^{2}=99.16 \%\right.$ (98.98 to $\left.99.32 \%\right) ; \mathrm{p}<$ 0.0001 ; random effect; 12 studies; $\mathrm{n}=1,206]$.

\section{Discussion}

A multitude of studies have made it clear that COVID-19 has significantly affected individuals of all ages. Although the virus is known to particularly target the lungs, it is not uncommon for the disease to manifest in other organ systems, especially in severe cases. More specifically, various pathological studies have particularly highlighted the kidneys as a target of COVID-19 with the development of AKI in critically ill COVID-19 adult patients. There have also been instances of AKI occurrence in pediatric COVID-19 patients. However, there has been no consensus regarding the accurate incidence, outcomes, and associated mortality among this population. Therefore, our systematic review and meta-analysis was performed to specifically address the incidence, mortality, outcomes, and various treatment modalities utilized in COVIDpositive pediatric patients with AKI.
Table 3 Quality criteria checklist assessment for the studies

\begin{tabular}{|c|c|c|c|c|c|c|}
\hline Study & $\begin{array}{l}\text { Inclusion } \\
\text { and } \\
\text { exclusion } \\
\text { specified }\end{array}$ & $\begin{array}{l}\text { Study } \\
\text { type }\end{array}$ & $\begin{array}{l}\text { Sample } \\
\text { size } \\
\text { specified }\end{array}$ & $\begin{array}{l}\text { COVID test } \\
\text { mentioned }\end{array}$ & $\begin{array}{l}\text { AKI } \\
\text { related } \\
\text { labs }\end{array}$ & $\begin{array}{l}\text { Management } \\
\text { mentioned }\end{array}$ \\
\hline $\begin{array}{l}\text { *González-Dambrauskas } \\
\text { S et al. }\end{array}$ & $\mathrm{Y}$ & $\mathrm{R}$ & $\mathrm{Y}$ & $\mathrm{Y}$ & $\mathrm{N}$ & $\mathrm{Y}$ \\
\hline *Whittaker E et al. & N/A & $\mathrm{CS}$ & $\mathrm{Y}$ & $\mathrm{Y}$ & $\mathrm{Y}$ & $\mathrm{Y}$ \\
\hline *Dufort EM et al. & $\mathrm{Y}$ & $\mathrm{R}$ & $\mathrm{Y}$ & $\mathrm{Y}$ & $\mathrm{N}$ & Y \\
\hline *Lee PY et al. & $\mathrm{Y}$ & $\mathrm{R}$ & $\mathrm{Y}$ & $\mathrm{Y}$ & $\mathrm{Y}$ & $\mathrm{Y}$ \\
\hline Capone CA et al. & N/A & $\mathrm{CS}$ & $\mathrm{Y}$ & $\mathrm{Y}$ & $\mathrm{N}$ & $\mathrm{Y}$ \\
\hline Wang $X$ et al. & & $\mathrm{R}$ & $\mathrm{Y}$ & $\mathrm{Y}$ & $\mathrm{Y}$ & $\mathrm{Y}$ \\
\hline Tram $\mathrm{N}$ et al. & N/A & $\mathrm{CR}$ & $\mathrm{Y}$ & $\mathrm{Y}$ & $\mathrm{Y}$ & $\mathrm{Y}$ \\
\hline Samies NL et al. & N/A & $\mathrm{CR}$ & $\mathrm{Y}$ & $\mathrm{Y}$ & $\mathrm{Y}$ & $\mathrm{Y}$ \\
\hline Repper DC et al. & N/A & $\mathrm{CR}$ & $\mathrm{Y}$ & $\mathrm{Y}$ & $\mathrm{Y}$ & $\mathrm{Y}$ \\
\hline Qiu L et al. & N/A & $\mathrm{CR}$ & $\mathrm{Y}$ & $\mathrm{Y}$ & $\mathrm{Y}$ & $\mathrm{Y}$ \\
\hline Niño-Taravilla C et al. & N/A & $\mathrm{CR}$ & $\mathrm{Y}$ & Y & Y & $\mathrm{Y}$ \\
\hline *Mamishi S et al. & $\mathrm{Y}$ & $\mathrm{R}$ & $\mathrm{Y}$ & Y & $\mathrm{Y}$ & $\mathrm{Y}$ \\
\hline Lee $\mathrm{M}$ et al. & N/A & $\mathrm{CR}$ & $\mathrm{Y}$ & $\mathrm{Y}$ & $\mathrm{Y}$ & $\mathrm{Y}$ \\
\hline Grimaud $\mathrm{M}$ et al. & $\mathrm{Y}$ & $\mathrm{R}$ & $\mathrm{N}$ & $\mathrm{Y}$ & $\mathrm{Y}$ & $\mathrm{Y}$ \\
\hline Oberweis ML et al. & N/A & $\mathrm{CR}$ & $\mathrm{Y}$ & $\mathrm{Y}$ & $\mathrm{Y}$ & $\mathrm{Y}$ \\
\hline *Toubiana $\mathrm{J}$ et al. & $\mathrm{Y}$ & $\mathrm{P}$ & $\mathrm{Y}$ & $\mathrm{Y}$ & $\mathrm{Y}$ & $\mathrm{Y}$ \\
\hline Shahbaznejad, L et al. & N/A & $\mathrm{CS}$ & $\mathrm{Y}$ & $\mathrm{Y}$ & $\mathrm{N}$ & $\mathrm{Y}$ \\
\hline *Godfred-Cato S et al. & $\mathrm{Y}$ & $\mathrm{R}$ & $\mathrm{Y}$ & $\mathrm{Y}$ & $\mathrm{N}$ & Y \\
\hline *Dionne A et al. & $\mathrm{Y}$ & $\mathrm{R}$ & $\mathrm{Y}$ & $\mathrm{Y}$ & $\mathrm{N}$ & $\mathrm{Y}$ \\
\hline *Derespina KR et al. & $\mathrm{Y}$ & $\mathrm{R}$ & $\mathrm{Y}$ & $\mathrm{Y}$ & $\mathrm{Y}$ & $\mathrm{Y}$ \\
\hline Stewart DJ et al. & $\mathrm{Y}$ & $\mathrm{R}$ & $\mathrm{Y}$ & $\mathrm{Y}$ & $\mathrm{Y}$ & $\mathrm{N}$ \\
\hline *Bjornstad EC et al. & $\mathrm{Y}$ & $\mathrm{CrS}$ & $\mathrm{Y}$ & $\mathrm{Y}$ & $\mathrm{Y}$ & $\mathrm{N}$ \\
\hline Deep A et al. & $\mathrm{Y}$ & $\mathrm{R}$ & $\mathrm{N}$ & $\mathrm{N}$ & $\mathrm{N}$ & $\mathrm{N}$ \\
\hline Joshi K et al. & N/A & $\mathrm{CS}$ & $\mathrm{Y}$ & $\mathrm{Y}$ & $\mathrm{N}$ & $\mathrm{Y}$ \\
\hline
\end{tabular}

$Y$ yes, $N$ no, $R$ retrospective, $P$ prospective, $C S$ case series, $C R$ case report, $C r S$ cross sectional, $N / A$ not applicable *The studies included in the meta-analysis 
Table 4 Meta-analysis of pediatric $\mathrm{AKI}$ incidence among COVID positive patients across different studies

\begin{tabular}{llll}
\hline Study & Event/sample size & $\begin{array}{l}\text { Proportion (\%) } \\
(95 \% \text { CI })\end{array}$ & Random weight (\%) \\
\hline Bjornstad EC et al., 2020 & $47 / 106$ & $44.34(34.69-54.31)$ & 7.95 \\
Capone CA et al., 2020 & $23 / 33$ & $69.70(51.29-84.41)$ & 6.87 \\
Deep A et al., 2020 & $48 / 116$ & $41.38(32.31-50.90)$ & 8.00 \\
Derespina KR et al., 2020 & $9 / 70$ & $12.86(6.05-23.01)$ & 7.66 \\
Dionne et al., 2020 & $2 / 25$ & $8.00(0.98-26.03)$ & 6.48 \\
Dufort EM et al., 2020 & $10 / 99$ & $10.10(4.95-17.79)$ & 7.91 \\
Godfred-Cato S et al., 2020 & $105 / 570$ & $18.42(15.32-21.85)$ & 8.45 \\
González-Dambrauskas S et al., 2020 & $3 / 17$ & $17.65(3.80-43.43)$ & 5.84 \\
Grimaud M et al., 2020 & $14 / 20$ & $70.00(45.72-88.11)$ & 6.12 \\
Lee PY et al., 2020 & $6 / 28$ & $21.43(8.30-40.95)$ & 6.64 \\
Mamishi S et al., 2020 & $13 / 45$ & $28.89(16.37-44.32)$ & 7.25 \\
Stewart DJ et al., 2020 & $15 / 52$ & $28.85(17.13-43.08)$ & 7.40 \\
Toubiana J et al., 2020 & $11 / 21$ & $52.38(29.78-74.29)$ & 6.20 \\
Whittaker E et al., 2020 & $11 / 45$ & $24.44(12.88-39.54)$ & 7.25 \\
Total (random effects) & $317 / 1,247$ & $30.51(21.84-39.94)$ & 100 \\
\hline
\end{tabular}

In our meta-analysis, we found an AKI incidence of $30.51 \%$ (21.84-39.94\%). The higher incidence among pediatric patients was higher than we expected, however, in the multicenter cohort study (the Critical Coronavirus and Kids Epidemiologic [CAKE] study) of critically ill children with COVID-19, the incidence of AKI was reported to be $18 \%$ [13]. Additionally, in a multicenter AKI study among critically ill children with COVID-19 by Bjornstad et al. $(\mathrm{n}=106)$, AKI was found to occur in $44 \%(n=47)$ of patients [14]. We also found a mortality of $2.55 \%(1.67-3.73 \%)$ in COVID AKI patients with $0.56 \%$ of patients requiring KRT $(0.16-1.43 \%)$. This is similar to the data reported by the Virtual Pediatric Systems (VPS) from North American pediatric ICUs as of February 2020. Based on the 2,030 COVID-19 positive patients reported by VPS, there was a mortality rate of $3.3 \%$
(Fig. 6c). Additionally, in the 281 (13.8\%) of COVID-19 patients with kidney systems involved, there was a mortality rate of $10.3 \%(n=29)$ with $13.9 \%(n=39)$ requiring organ support via KRT. Lastly, it had been reported by various studies that some pediatric patients uniquely exhibited MIS-C. A recent systematic review by Abrams et al. analyzing the clinical features of 440 children with MIS-C revealed that the proportion of patients who received a positive SARS-CoV-2 RT-PCR test ranged from 13 to $60 \%$ while the proportion of positive serology tests ranged from 75 to $100 \%$ [36]. Additionally, Feldstein et al. reported that out of 186 children with MIS-C, $70 \%$ were COVID-positive by RT-PCR or antibody testing [10]. Based on our review, we found that the pooled incidence (95\% CI) of MIS-C among COVID-positive patients was $74.29 \%(41.24-96.43 \%)$ [p $<0.0001 ;$ random effect; 12
Fig. 2 Forest plot of the metaanalysis of pediatric AKI incidence among COVID-positive patients across different studies. The lower diamond in the graph represents the pooled estimate

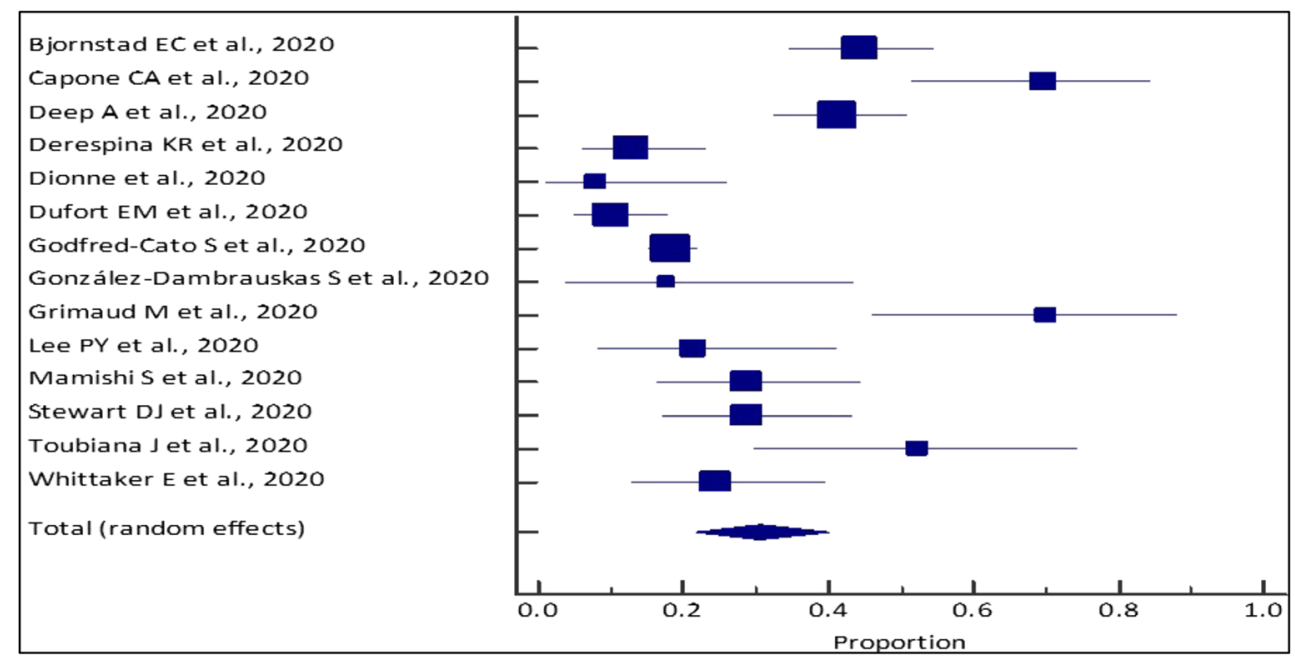


Fig. 3 Funnel plot for pediatric AKI incidence among COVIDpositive patients

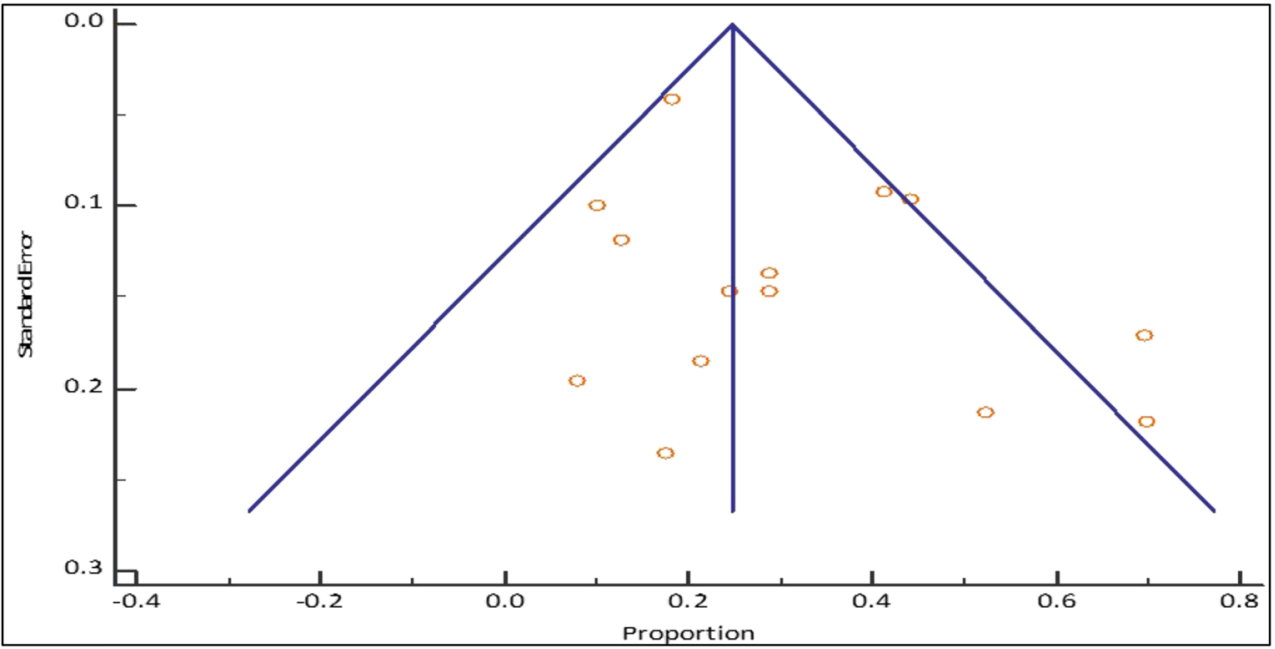

studies; $n=1,206]$. This is much higher than reported by VPS, which reported a total of $23.9 \%$ of pediatric patients with MIS-C (485 out of 2,030 patients). These differences may potentially be attributed to variations in the definition and clinical knowledge of the syndrome due to its novelty [7].

To bring our pediatric data into comparison with adult data regarding AKI in COVID-positive patients, a sub-analysis was performed with our systematic review which assessed AKI incidence in the majority of adult COVID patients. The parameters of our adult systematic review are highlighted in Appendix C. Our comparison analysis was performed by calculating medians and utilizing the Mann-Whitney U-test with a $\mathrm{p}$ value $\leq 0.05$ considered for statistical significance (Fig. 6a). The pooled median age of children was 9.1 years (ranging from median of 6.5-14.5 years across all studies) and adults was 61 years (median of 45.6-73 years). The proportion of males was almost equal for children (56.2\%) and adult $(60.9 \%)$ studies. However, there was a lower proportion of children $(26.7 \%)$ with at least 1 pre-existing co-morbidity than that of adults $(40.9 \%)$.
The median (IQR) AKI incidence was calculated for both populations and was found to be higher among pediatric patients [26.6\% $(17.8-43.6 \%) ; \mathrm{n}=14] \mathrm{com}-$ pared to the adult population $[15.6 \%(5.7-31.7 \%) ; \mathrm{n}=$ 53] $(\mathrm{p}=0.07)$. Mortality was also compared and the median (IQR) mortality among COVID-positive patients was observed to be significantly lower among pediatric patients $[1.9 \%(0.0-4.8 \%) ; \mathrm{n}=10]$ compared to adults [14.6\% (5.4-39.3\%); $\mathrm{n}=25](\mathrm{p}<0.001)$ (Fig. 6b). In respect to the utilization of KRT among COVIDpositive patients, the median utilization was significantly lower among pediatric patients $[0.2 \%(0.0-0.6 \%) ; \mathrm{n}=$ 4] when compared to adults [8.0\% (3.3-16.7\%); $\mathrm{n}=33]$ ( $\mathrm{p}<0.001$ ) (Fig. 6b).

Overall, this suggests that children may have less severe symptoms from SARS-CoV-2 as compared to adults. The observed outcomes among children may be attributed to a more active innate immune response, generally being overprotected by parents, engaging in fewer outdoor activities, undertaking less international
Table 5 Meta-analysis of pediatric mortality among COVID positive patients across different studies

\begin{tabular}{llll}
\hline Study & Event/sample size & $\begin{array}{l}\text { Proportion (\%) } \\
(95 \% \text { CI })\end{array}$ & Fixed weight (\%) \\
\hline Bjornstad EC et al., 2020 & $6 / 106$ & $5.66(2.11-11.91)$ & 10.71 \\
Capone CA et al., 2020 & $0 / 33$ & $0(0-10.58)$ & 3.40 \\
Dionne et al., 2020 & $0 / 25$ & $0(0-13.72)$ & 2.60 \\
Dufort EM et al., 2020 & $2 / 99$ & $2.02(0.25-7.11)$ & 10.01 \\
Godfred-Cato S et al., 2020 & $10 / 570$ & $1.75(0.84-3.2)$ & 57.16 \\
González-Dambrauskas S et al., 2020 & $1 / 17$ & $5.88(0.15-28.69)$ & 1.80 \\
Lee PY et al., 2020 & $0 / 28$ & $0(0-12.34)$ & 2.90 \\
Mamishi S et al., 2020 & $5 / 45$ & $11.11(3.71-24.05)$ & 4.60 \\
Toubiana J et al., 2020 & $0 / 21$ & $0(0-16.11)$ & 2.20 \\
Whittaker E et al., 2020 & $1 / 45$ & $2.22(0.06-11.77)$ & 4.60 \\
Total (fixed effects) & $\mathbf{2 5 / 9 8 9}$ & $\mathbf{2 . 5 5 ( 1 . 6 7 - 3 . 7 3 )}$ & $\mathbf{1 0 0}$ \\
\hline
\end{tabular}


Fig. 4 Forest plot of the metaanalysis of pediatric mortality among COVID-positive patients across different studies. The lower diamond in the graph represents the pooled estimate

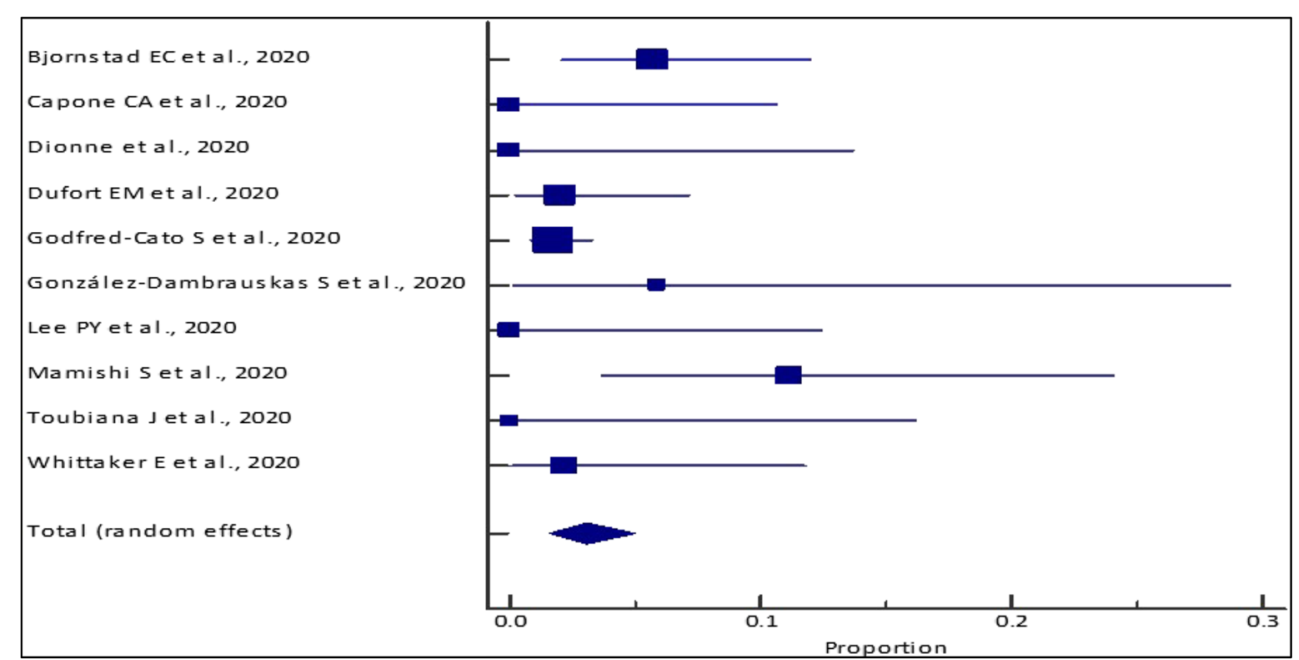

children with COVID-19 receiving care in high-income countries versus low- and middle-income countries. In comparison to high-income countries, low- and middleincome countries report lower proportions of admissions to the ICU $(9.9 \%$ vs. $26.0 \%)$, yet higher numbers of deaths (relative risk 2.14, 95\% CI: 1.43 to 3.20) [9]. This suggests that more large-scale global studies are required to fully assess the extent of AKI in pediatric COVID patients.

Although our study was able to accurately determine outcomes in COVID patients, one of the main limitations in our study was the sample size, as COVID and AKI incidence reports are still new. Due to a paucity of literature, it restricted us from doing a detailed analysis. Additionally, some studies presented insufficient data, forcing us to exclude them from our analysis despite meeting our inclusion criteria. It is also important to note that in our analysis, only studies with a sample size greater than 10 were included to remove the influence on outcome by studies with small sample sizes.
Fig. 5 Funnel plot for pediatric mortality among COVID-positive patients

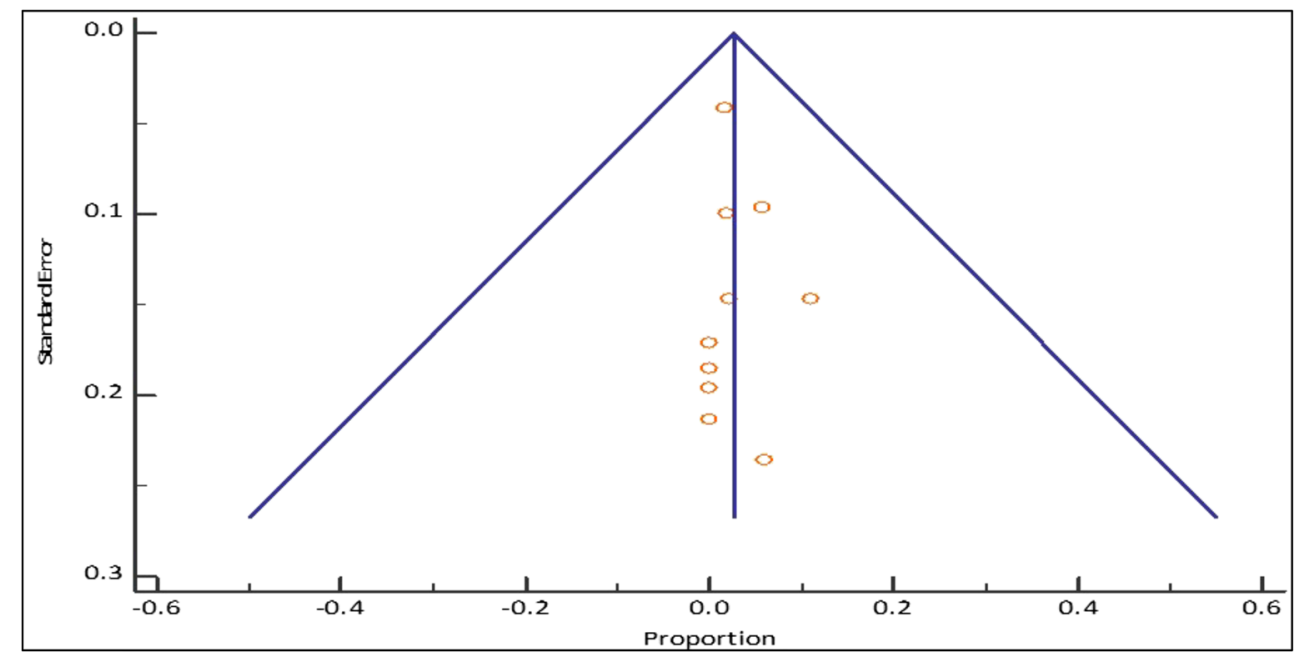


a

\begin{tabular}{|l|c|c|}
\hline & Adults & Children \\
\hline COVID+ Individuals & 42,591 & 1,247 \\
\hline Median Age (years) & 61 & 9.1 \\
\hline
\end{tabular}

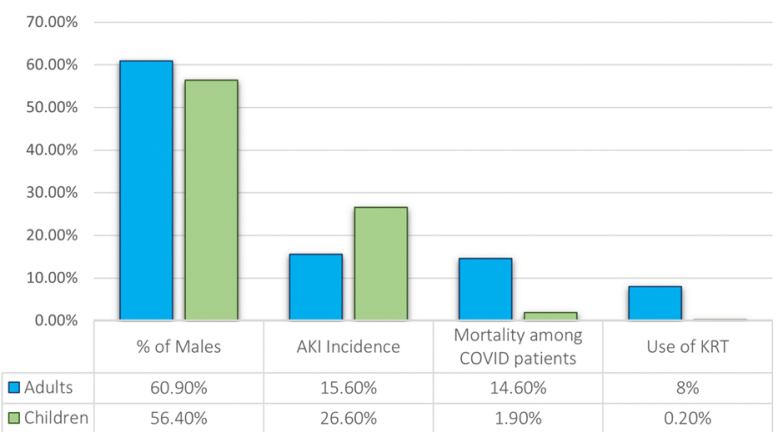

b

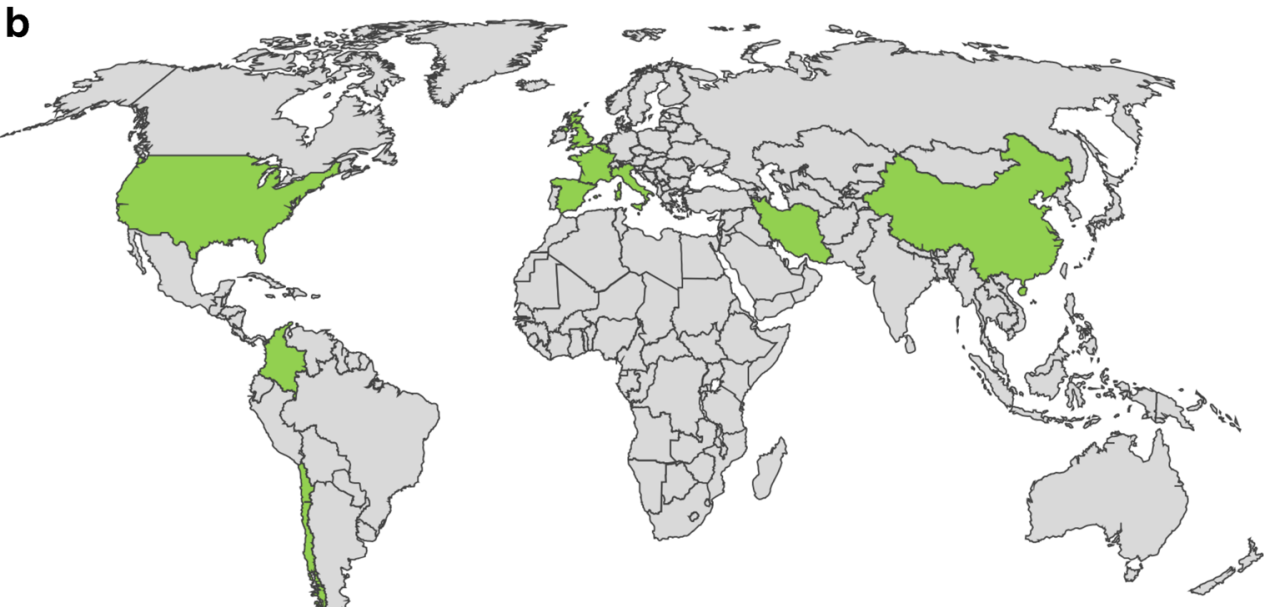

The countries highlighted in green indicate the location of the pediatric studies.

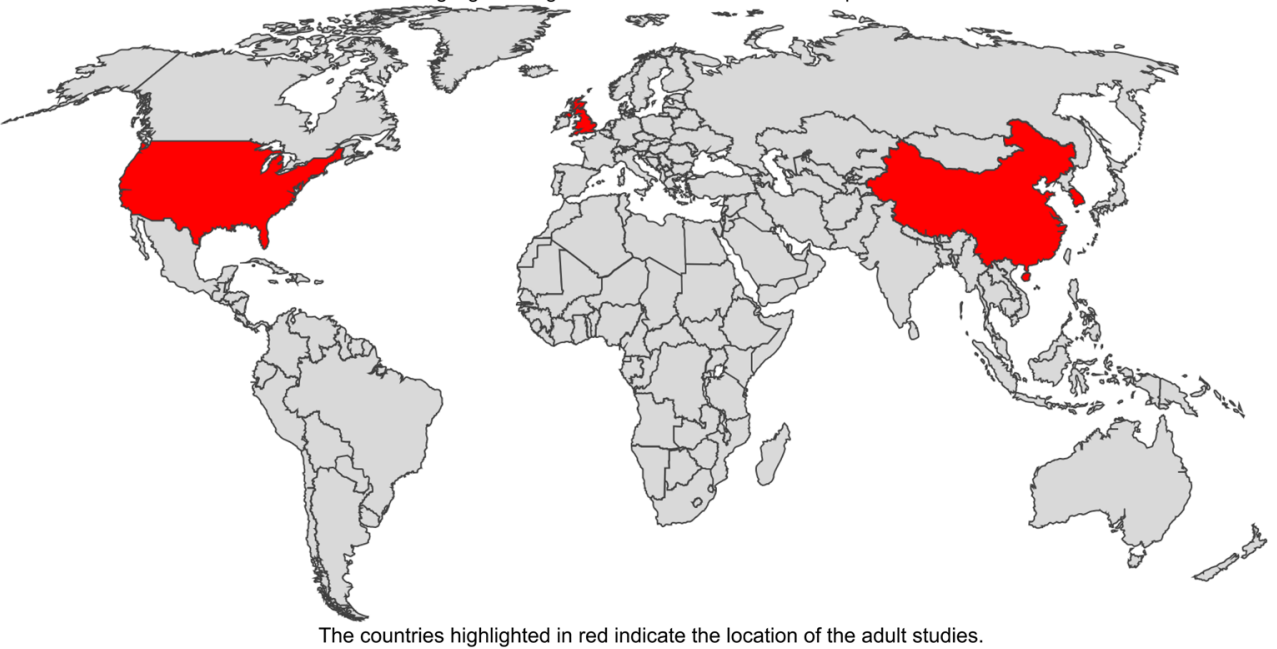

\begin{tabular}{|l|c|}
\hline COVID-19 patients & 2030 \\
\hline Confirmed deaths & 66 \\
\hline MIS-C Diagnosis & 485 \\
\hline $\begin{array}{l}\text { Patients with } \\
\text { renal/urinary } \\
\text { manifestations }\end{array}$ & 281 \\
\hline $\begin{array}{l}\text { Patients requiring } \\
\text { Kidney replacement } \\
\text { therapy }\end{array}$ & 39 \\
\hline
\end{tabular}


Fig. 6 (a) Comparison of the adult vs. pediatric COVID-19 population. (b) World map of pediatric vs. adult COVID-19 studies. (c) COVID-19 clinical data from North American pediatric intensive care units (https:// www.covid19.myvps.org)

\section{Conclusion}

Overall, AKI has shown to be a negative prognostic factor in adult patients with AKI and now also in the pediatric cohort with high incidence and mortality rates. Additionally, our findings do show a strong comparison in epidemiology between adult and pediatric COVID-19 patients; however, they need to be confirmed with additional data and studies as the direction of the relationships cannot be ascertained and still remain unclear in the literature. With the prevalence of cases worldwide, it is crucial for clinicians to be informed about the prevalence of AKI in both adult and pediatric populations.

Supplementary Information The online version contains supplementary material available at https://doi.org/10.1007/s00467-021-05084-x.

Acknowledgements We would like to thank Dr. Kirsten Kusumi from the Akron Children's Hospital for medically editing the manuscript. We would also like to thank Ms. Simonson from the Cleveland Clinic Foundation Library and the Akron Children's Library for her aid in the data search and Dr. Abhishek Tibrewal for his contribution with the data review and statistical analysis.

Author contribution RR conceptualized the study. RR, RC, IM, SS, and MF drafted the study protocol, conducted the literature search, study screening, selection and data extraction, and drafted the manuscript. All authors critically reviewed the manuscript to ensure intellectual content and approved the final manuscript.

Funding There is none to report.

\section{Declarations}

Patient consent for publication Not required.

Conflict of interest The authors declare no competing interest.

\section{References}

1. World Health Organization (2020) Statement on the second meeting of the International Health Regulations (2005) Emergency Committee regarding the outbreak of novel coronavirus (2019nCoV). https://www.who.int/news-room/detail/30-01-2020statement-on-thesecond-meeting-of-the-internationalhealthregulations-(2005)-emergency-committee-regarding-the-outbreakof-novel-coronavirus-(2019-ncov)

2. Raina R, Chakraborty R, Sethi SK, Bunchman T (2020) Kidney replacement therapy in COVID-19 induced kidney failure and septic shock: a pediatric continuous renal replacement therapy [PCRRT] position on emergency preparedness with resource allocation. Front Pediatr 8:413. https://doi.org/10.3389/fped.2020. 00413
3. Gabarre P, Dumas G, Dupont T, Darmon M, Azoulay E, Zafrani L (2020) Acute kidney injury in critically ill patients with COVID-19. Intensive Care Med 46:1339-1348. https://doi.org/10.1007/ s00134-020-06153-9

4. Wu Z, McGoogan JM (2020) Characteristics of and important lessons from the coronavirus disease 2019 (COVID-19) outbreak in China: summary of a report of 72314 cases from the Chinese Center for Disease Control and Prevention. JAMA 323:12391242. https://doi.org/10.1001/jama.2020.2648

5. Qiu H, Wu J, Hong L, Luo Y, Song Q, Chen D (2020) Clinical and epidemiological features of 36 children with coronavirus disease 2019 (COVID-19) in Zhejiang, China: an observational cohort study. Lancet Infect Dis 20:689-696. https://doi.org/10.1016/ S1473-3099(20)30198-5

6. Rabinowicz S, Leshem E, Pessach IM (2020) COVID-19 in the pediatric population-review and current evidence. Curr Infect Dis Rep 22:29. https://doi.org/10.1007/s1 1908-020-00739-6

7. Harwood R, Allin B, Jones CE, Whittaker E, Ramnarayan P, Ramanan AV et al (2021) A national consensus management pathway for paediatric inflammatory multisystem syndrome temporally associated with COVID-19 (PIMS-TS): results of a national Delphi process. Lancet Child Adolesc Health 5:133-141 Erratum 5:e5. https://doi.org/10.1016/S2352-4642(20)30304-7

8. Deep A, Bansal M, Ricci Z (2021) Acute kidney injury and special considerations during renal replacement therapy in children with coronavirus disease-19: perspective from the Critical Care Nephrology Section of the European Society of Paediatric and Neonatal Intensive Care. Blood Purif 50:150-160. https://doi.org/ $10.1159 / 000509677$

9. Irfan O, Muttalib F, Tang K, Jiang L, Lassi ZS, Bhutta Z (2021) Clinical characteristics, treatment and outcomes of paediatric COVID-19: a systematic review and meta-analysis. Arch Dis Child. https://doi.org/10.1136/archdischild-2020-321385

10. Feldstein LR, Rose EB, Horwitz SM, Collins JP, Newhams MM, Son MBF et al (2020) Multisystem inflammatory syndrome in U.S. children and adolescents. N Engl J Med 383:334-346. https://doi. org/10.1056/NEJMoa2021680

11. Levin M (2020) Childhood multisystem inflammatory syndrome - a new challenge in the pandemic. N Engl J Med 383:393-395. https:// doi.org/10.1056/NEJMe2023158

12. Jiang L, Tang K, Levin M, Irfan O, Morris SK, Wilson $\mathrm{K}$ et al (2020) COVID-19 and multisystem inflammatory syndrome in children and adolescents. Lancet Infect Dis 20:e276-e288. https:// doi.org/10.1016/S1473-3099(20)30651-4

13. González-Dambrauskas S, Vásquez-Hoyos P, Camporesi A, DíazRubio F, Piñeres-Olave BE, Fernández-Sarmiento J et al (2020) Pediatric critical care and COVID-19. Pediatrics 146:e20201766. https://doi.org/10.1542/peds.2020-1766

14. Bjornstad EC, Krallman KA, Askenazi D, Zappitelli M, Goldstein SL, Basu RK et al (2020) Preliminary assessment of acute kidney injury in critically ill children associated with SARS-CoV-2 infection: a multicenter cross-sectional analysis. Clin J Am Soc Nephrol 16:446-448. https://doi.org/10.2215/CJN.11470720

15. Whittaker E, Bamford A, Kenny J, Kaforou M, Jones CE, Shah P et al (2020) Clinical characteristics of 58 children with a pediatric inflammatory multisystem syndrome temporally associated with SARS-CoV-2. JAMA 324:259-269. https://doi.org/10.1001/jama. 2020.10369

16. Dufort EM, Koumans EH, Chow EJ, Rosenthal EM, Muse A, Rowlands J (2020) Multisystem inflammatory syndrome in children in New York State. N Engl J Med 383:347-358. https://doi. org/10.1056/NEJMoa2021756

17. Lee PY, Day-Lewis M, Henderson LA, Friedman K, Lo J, Roberts JE (2020) Distinct clinical and immunological features of SARSCOV-2-induced multisystem inflammatory syndrome in children. J Clin Invest 130:5942-5950. https://doi.org/10.1172/JCI141113 
18. Capone CA, Subramony A, Sweberg T, Schneider J, Shah S, Lorry $R$ et al (2020) Characteristics, cardiac involvement, and outcomes of multisystem inflammatory syndrome of childhood associated with severe acute respiratory syndrome coronavirus 2 Infection. J Pediatr 224:141-145. https://doi.org/10.1016/j.jpeds.2020.06.044

19. Wang X, Chen X, Tang F, Luo W, Fang J, Chang Q et al (2021) Be aware of acute kidney injury in critically ill children with COVID19. Pediatr Nephrol 36:163-169. https://doi.org/10.1007/s00467020-04715-Z

20. Tram N, Chiodini B, Montesinos I, Vicinanaza A, Piccoli XB, Gubbelmans N et al (2020) Rhabdomyolysis and acute kidney injury as leading COVID-19 presentation in an adolescent. Pediatr Infect Dis J 39:e314-e315. https://doi.org/10.1097/INF. 0000000000002853

21. Samies NL, Pinninti S, James SH (2020) Rhabdomyolysis and acute renal failure in an adolescent with coronavirus disease 2019. J Pediatric Infect Dis Soc 9:507-509. https://doi.org/10.1093/jpids/ piaa083

22. Repper DC, Arrieta AC, Cook JE, Renella P (2020) A case of Lemierre syndrome in the era of COVID-19: all that glitters is not gold. Pediatr Infect Dis J 39:e445-e447. https://doi.org/10.1097/ INF.0000000000002939

23. Qiu L, Jiao R, Zhang A, Chen X, Ning Q, Fang F et al (2020) A case of critically ill infant of coronavirus disease 2019 with persistent reduction of T lymphocytes. Pediatr Infect Dis J 39:e87-e90. https://doi.org/10.1097/INF.0000000000002720

24. Niño-Taravilla C, Espinosa-Vielma YP, Otaola-Arca H, PoliHarlowe C, Tapia LI, Ortiz-Fritz P (2020) Pediatric inflammatory multisystem syndrome temporally associated with SARS-CoV-2 treated with tocilizumab. Pediatr Rep 12:142-148. https://doi.org/ 10.3390/pediatric12030029

25. Mamishi S, Movahedi Z, Mohammadi M, Ziaee V, Khodabandeh M, Abdolsalehi MR et al (2020) Multisystem inflammatory syndrome associated with SARS-CoV-2 infection in 45 children: a first report from Iran. Epidemiol Infect 148:e196. https://doi.org/10. 1017/S095026882000196X

26. Lee M, Hilado M, Sotelo S, Opas LM, Im DD (2020) Acute kidney injury in Multisystem Inflammatory Syndrome in Children (MISC): a case report. SN Compr Clin Med 1-4. https://doi.org/10.1007/ s42399-020-00647-9

27. Grimaud M, Starck J, Levy M, Marais C, Chareyre J, Khraiche D et al (2020) Acute myocarditis and multisystem inflammatory emerging disease following SARS-CoV-2 infection in critically ill children. Ann Intensive Care 10:69-68. https://doi.org/10.1186/ s13613-020-00690-8

28. Oberweis ML, Codreanu A, Boehm W, Olivier D, Pierron C, Tsobo $\mathrm{C}$ et al (2020) Pediatric life-threatening coronavirus disease 2019 with myocarditis. Pediatr Infect Dis J 39:e147-e149. https://doi. org/10.1097/INF.0000000000002744

29. Toubiana J, Poirault C, Corsia A, Bajolle F, Fourgeaud J, Angoulvant $\mathrm{F}$ et al (2020) Kawasaki-like multisystem inflammatory syndrome in children during the covid-19 pandemic in Paris, France: prospective observational study. BMJ 369:m2094. https:// doi.org/10.1136/bmj.m2094
30. Shahbaznejad L, Navaeifar M, Abbaskhanian A, Hosseinzadeh F, Rahimzadeh G, Rezai MS et al (2020) Clinical characteristics of 10 children with a pediatric inflammatory multisystem syndrome associated with COVID-19 in Iran. BMC Pediatr 20:513. https://doi. org/10.1186/s12887-020-02415-Z

31. Godfred-Cato S, Bryant B, Leung J, Oster ME, Conklin L, Abrams $\mathrm{J}$ et al (2020) COVID-19-associated multisystem inflammatory syndrome in children - United States, March-July 2020. Morb Mortal Wkly Rep 69:1074-1080. https://doi.org/10.15585/mmwr. mm6932e2

32. Dionne A, Mah DY, Son M, Lee PY, Henderson L, Baker AL et al (2020) Atrioventricular block in children with multisystem inflammatory syndrome. Pediatrics 146:e2020009704. https://doi.org/10. 1542/peds.2020-009704

33. Derespina KR, Kaushik S, Plichta A, Nadkarni VM, Agus MSD, Medar SS et al (2020) Clinical manifestations and outcomes of critically ill children and adolescents with coronavirus disease 2019 in New York City. J Pediatr 226:55-63.e2. https://doi.org/ 10.1016/j.jpeds.2020.07.039

34. Stewart DJ, Hartley JC, Johnson M, Marks SD, du Pré P, Stojanovic J (2020) Renal dysfunction in hospitalised children with COVID-19. Lancet Child Adolesc Health 4:e28-e29. https://doi. org/10.1016/S2352-4642(20)30178-4

35. Deep A, Upadhyay G, du Pré P, Lillie J, Pan D, Mudalige N et al (2020) Acute kidney injury in pediatric inflammatory multisystem syndrome temporally associated with severe acute respiratory syndrome coronavirus-2 pandemic: experience from PICUs across United Kingdom. Crit Care Med 48:1809-1818. https://doi.org/ 10.1097/CCM.0000000000004662

36. Abrams JY, Godfred-Cato SE, Oster ME, Chow EJ, Koumans EH, Bryant B et al (2020) Multisystem inflammatory syndrome in children associated with severe acute respiratory syndrome coronavirus 2: a systematic review. J Pediatr 226:45-54.e1. https://doi.org/10. 1016/j.jpeds.2020.08.003

37. Dong Y, Mo X, Hu Y, Qi X, Jiang F, Jiang Z et al (2020) Epidemiology of COVID-19 among children in China. Pediatrics 145:e20200702. https://doi.org/10.1542/peds.2020-0702

38. South AM, Brady TM, Flynn JT (2020) ACE2 (angiotensinconverting enzyme 2), COVID-19, and ACE inhibitor and Ang II (Angiotensin II) receptor blocker use during the pandemic: the pediatric perspective. Hypertension 76:16-22. https://doi.org/10. 1161/HYPERTENSIONAHA.120.15291

39. Lee PI, Hu YL, Chen PY, Huang YC, Hsueh PR (2020) Are children less susceptible to COVID-19? J Microbiol Immunol Infect 53:371-372. https://doi.org/10.1016/j.jmii.2020.02.011

40. Xu Z, Shi L, Wang Y, Zhang J, Huang L, Zhang C et al (2020) Pathological findings of COVID-19 associated with acute respiratory distress syndrome. Lancet Respir Med 8:420-422. https://doi. org/10.1016/S2213-2600(20)30076-X

Publisher's note Springer Nature remains neutral with regard to jurisdictional claims in published maps and institutional affiliations. 